*Mestranda em Ciências Jurídicas pelo Centro Universitário de Maringá - UniCesumar, com enfoque nos Direitos da Personalidade e seu alcance na contemporaneidade. Bolsista do Programa de Suporte à PósGraduação de Instituições de Ensino Particulares (PROSUP/ CAPES). Graduada no Curso de Direito da Instituição de Ensino Superior Unicesumar, da cidade de Maringá-PR (2013-2017). Pós-Graduanda em Docência no Ensino Superior. Membra do grupo de Pesquisa "Proteção Integral da Pessoa: Interações dos Direitos Humanos, dos Direitos Fundamentais e dos Direitos da Personalidade. Advogada no Paraná. mylenemanfrinato@ gmail.com.

** Possui graduação em Direito pela Universidade Estadual de Maringá (1991), mestrado em Direito Negocial com área específica em Trabalho e Processo do Trabalho pela Universidade Estadual de Londrina (1997) e doutorado em Filosofia do Direito pela Pontifícia Universidade Católica de São Paulo (2004). Pós-Doutor na Universidade de Lisboa. Atualmente é professor concursado titular em Direito e Processo do Trabalho na Universidade Estadual de Maringá, Professor da Faculdade de Ciências Sociais Aplicadas de Cascavel Univel, professor titular - Faculdades Maringá, professor da União de Faculdades Metropolitana de Maringá, professor T-40 do Centro Universitário de Maringá. Tem experiência na área de Direito, com ênfase em Direito Constitucional, Direito e Processo do Trabalho, Filosofia do Direito, atuando principalmente nos seguintes temas: transdisciplinariedade, contemporaneidade, trabalho, prova e dignidade. asvzenni@ hotmail.com.

\section{A Utilização Da Reprodução Humana Assistida \\ E Seus Efeitos No Direito de Família E Direito Sucessório Sob A Ótica Do Princípio Da Dignidade Da Pessoa Humana}

\author{
The Use Of Assisted Human Reproduction And Its
}

EfFects On Family Law And Inheritance LaW From The Perspective Of The Principle Of The Dignity Of The Human PERSON

\section{Mylene Manfrinato dos Reis Amaro* Alessandro Severino Vallér Zenni**}

Como citar: AMARO, Mylene Manfrinato dos Reis; ZENNI, Alessandro Severino Vallér. A UTILIZAÇÃO DA REPRODUÇÃO HUMANA ASSISTIDA E SEUS EFEITOS NO DIREITO DE FAMÍLIA E DIREITO SUCESSÓRIO SOB A ÓTICA DO PRINCÍPIO DA DIGNIDADE DA PESSOA HUMANA. Revista do Instituto de Direito Constitucional e Cidadania - IDCC, Londrina, v. 4, n. 2, p 31-44, dez, 2019. ISSN: 2596-0075.

https://doi.org/10.48159/revistadoidcc.v4n2.amaro.zenni

Resumo: A presente pesquisa tem por objetivo discutir sobre a reprodução humana assistida e suas consequências jurídicas frente ao Direito de Família e Sucessões, sob a ótica do princípio da dignidade da pessoa humana, principalmente no que tange às relações de parentesco e aos direitos sucessórios do filho, o que faz com que o conceito de filiação e de alguns institutos do direito sucessório sejam repensados. A respeito da temática, destaca-se que a Constituição Federal de 1988 possui como fundamento da democracia e pressuposto de respeito entre os indivíduos a dignidade da pessoa humana. Além disso, o ordenamento brasileiro consagra, além da filiação biológica e jurídica, a filiação civil ou a socioafetiva. E é justamente sob este prisma que o caráter biológico da filiação abre espaço também à afetividade, estendendo o direito de igualdade no âmbito dos direitos sucessórios à filiação adotiva, inclusive àqueles advindos fora da constância do casamento e aos gerados por meio de técnicas de reprodução humana assistida. Por isso, há proibição de qualquer tipo de discriminação ou diferenciação entre os filhos. Nesta perspectiva, é necessário que o Direito de Família e Sucessões seja aplicado de forma que atenda não só aos anseios 
daqueles que querem ter realizado o seu projeto parental, mas também e, principalmente, que assegure o melhor interesse da criança gerada através das técnicas de reprodução assistida.

Palavras-chave: Filiação. Fertilização in vitro. Inseminação.

Abstract: The aim of this research is to discuss the assisted human reproduction and its legal consequences in relation to family and succession law, from the viewpoint of the principle of the dignity of the human person, especially in relation to relations of kinship and To the inheritance rights of the child, which makes the concept of affiliation and some institutes of succession law rethought. Regarding the theme, it is noteworthy that the Federal constitution of 1988 has as the foundation of democracy and presupposition of respect among individuals the dignity of the human person. In addition, Brazilian planning establishes, in addition to biological and legal affiliation, civil or socioaffective affiliation. And it is precisely in this perspective that the biological character of affiliation opens space also to affectivity, extending the right of equality in the realm of inheritance rights to adoptive affiliation, including those coming out of the constancy of marriage and those generated by Means of assisted human reproduction techniques. Therefore, there is a prohibition of any kind of discrimination or differentiation between children. In this perspective, it is necessary that family and succession law be applied in a way that meets not only the desires of those who want to have carried out their parental project, but also and, mainly, to ensure the best interest of the child generated through Assisted reproduction techniques.

Key-words: Membership. In Vitro Fertilization. Insemination. 


\section{INTRODUÇÃO}

Com a utilização das técnicas de reprodução humana assistida, famílias com problemas de infertilidade têm a possibilidade de concretizar o seu projeto parental, uma vez que a evolução na seara da medicina viabilizou o desejo de muitos casais de alcançarem esse objetivo. Diante dessas possibilidades, o Direito de Família e Sucessões deve adaptar-se a essa nova realidade e garantir a igualdade de direitos e condições aos filhos advindos por meio de técnicas de reprodução humana assistida.

Nesse sentido, a presente pesquisa busca investigar as formas de utilização das técnicas de reprodução humana assistida, verificando seus efeitos, as partes envolvidas, o direito à identidade genética e o direito à sucessão, sob a ótica do princípio da dignidade da pessoa humana e do Direito de Família e Sucessões, uma vez que os avanços da medicina no aspecto das reproduções devem ser pautados em limites éticos, para que não haja violação de direitos fundamentais, já que a legislação brasileira não contempla muitas normas a respeito do tema.

De igual modo, o trabalho pretende analisar os efeitos jurídicos relacionados à maternidade e à paternidade decorrentes da reprodução humana assistida e das possibilidades que surgem frente à legislação atual, tanto no Direito de Família, como no Direito Sucessório. Possibilidades concretas, que podem gerar vários questionamentos jurídicos, como por exemplo a inseminação artificial post mortem, a técnica do bebê medicamento, questões quanto ao anonimato do doador na inseminação artificial heteróloga, entre outras hipóteses.

\section{DO PRINCÍPIO DA DIGNIDADE DA PESSOA HUMANA COMO LIMITE PARA AS TÉCNICAS DE REPRODUÇÃO HUMANA ASSISTIDA}

Segundo o filósofo Immanuel Kant, o homem é um ser racional, capaz de regular-se por meio de leis que a si mesmo impõe e que geram deveres. Logo, por meio de um dever temos uma lei universal, pela qual o ser humano utilizando-se da ética e da razão para tratar a si mesmo e a seus semelhantes como fim e nunca como meio. ${ }^{1}$

O princípio da dignidade da pessoa humana possui suas raízes no pensamento kantiano. Contudo, segundo o doutrinador Jorge Miranda, o princípio da dignidade da pessoa humana implica na ideia do ser humano como centro de tudo, e fim em tudo. O autor, seguindo os pensamentos de Kant, leciona:

Em primeiro lugar, a dignidade da pessoa é da pessoa concreta, na sua vida real e quotidiana; não é de um ser ideal e abstracto. É o homem ou a mulher, tal como existe, que a ordem jurídica considera irredutível e insubstituível e cujos direitos fundamentais a Constituição enuncia e protege. Em todo o homem e em toda a mulher estão presentes todas as faculdades da humanidade. ${ }^{2}$

1 KANT, Immanuel. Fundamentação da metafísica dos costumes e outros escritos, tradução de Leopoldo Holzbach, São Paulo: Martin Claret, 2004, p. 52.

2 MIRANDA, Jorge. Manual de direito constitucional, tomo IV, 2. ed. - Coimbra Editora, 1993, p. 169. 
A Constituição Federal de 1988, em seu art. $1^{\circ}$, inciso III, estabeleceu um Estado Democrático de Direito, fundamentado no princípio da dignidade da pessoa humana. Como entende Ingo Wolgang Sarlet, o constituinte, ao dispor sobre a dignidade da pessoa como fundamento da República, pretendeu que este princípio fosse a base dos direitos fundamentais e, consequentemente, o núcleo essencial da Constituição. ${ }^{3}$

Dessa forma, Ingo Wolgang Sarlet preconiza que a dignidade da pessoa humana é o que caracteriza e distingue cada indivíduo na sua personalidade, acarretando ao Estado e comunidade, respeito, gerando um complexo de direitos e deveres fundamentais, que possuem o cunho de proteção contra qualquer ato de natureza discriminatória ou degradante e desumano, tal princípio garantindo, tratamento digno e respeitoso ao ser humano, com o cunho de promover uma vida saudável, além de proporcional sua participação ativa nos destinos da própria existência da vida. ${ }^{4}$

Nesse mesmo sentido Sarlet diz:

Construindo sua concepção a partir da natureza racional do ser humano, Kant assinala que a autonomia da vontade, entendida como a faculdade de determinar a si mesmo e agir em conformidade com a representação de certas leis, é um atributo apenas encontrado nos seres racionais, constituindo-se no fundamento da dignidade da natureza humana. ${ }^{5}$

Quanto à dignidade da pessoa humana, Maria Berenice Dias prescreve que, a dignidade da pessoa humana foi elevada a fundamento da ordem jurídica, provocando uma opção expressa pela pessoa, consequentemente todos os institutos que tratam de direitos que estejam envolvidas pessoas, deve proporcional a realização da personalidade, elevando a pessoa como centro de proteção do direito. ${ }^{6}$

Dessa forma, se existe um fundamento primordial para a democracia brasileira, este certamente é o respeito ao princípio da dignidade da pessoa humana, que deve ser destituído de qualquer resquício de base religiosa e/ou metafísica, para que possa garantir que todos em sociedade, apesar de suas diferenças, possam ser tratados de forma digna e igualitária, com a mesma consideração e respeito. ${ }^{7}$

De mais a mais, com fundamento no princípio da dignidade da pessoa humana, existe o princípio do planejamento familiar que foi consagrado tanto em sede constitucional, no artigo 226,

3 SARLET, Ingo Wolgang. Dignidade da pessoa humana e direitos fundamentais na Constituição de 1988. Porto Alegre: Livraria do Advogado, 2001, p. 62.

4 SARLET, Ingo Wolgang. Dignidade da pessoa humana e direitos fundamentais na Constituição de 1988. Porto Alegre: Livraria do Advogado, 2001, p. 62.

5 SARLET, Ingo Wolgang. Dignidade da pessoa humana e direitos fundamentais na Constituição de 1988. Porto Alegre: Livraria do Advogado, 2001, p. 32.

6 DIAS. Berenice. Manual de Direito das Famílias. 5. ed. revista, atualizada e ampliada. $2^{\text {a }}$ tiragem. São Paulo Revista dos Tribunais, 2009. p. 61.

7 RABENHORST, Eduardo Ramalho. Dignidade humana e moralidade democrática. Brasília: Brasília Jurídica, 2001. p. 48. 
$\S 7^{\circ}$ da Constituição Federal ${ }^{8}$, quanto na esfera infraconstitucional, no artigo $1.565, \S 2^{\circ}$ do Código Civil. .

Infraconstitucionalmente, o mencionado princípio também se encontra regulamentado na Lei $\mathrm{n}^{\circ}$ 9.263/1996, que assegura o direito ao planejamento familiar, compreendido aqui como o conjunto de ações de regulação da fecundidade que garanta direitos iguais de constituição, limitação ou aumento da prole, a todo cidadão, independentemente de seu estado civil. ${ }^{10}$

Assim, tendo em vista que a Constituição Federal de 1988 e a Lei 9263/96 asseguram o direito ao livre planejamento familiar, uma vez esgotadas a possibilidade de reprodução natural, as pessoas podem recorrer à reprodução humana assistida como forma de viabilizar o desejo de constituição da prole. Entretanto, fundamental é que se compreenda que a dignidade da pessoa humana é um princípio que deve ser observado pelos que buscam a realização do projeto parental, especialmente se este utilizar técnicas de reprodução assistida.

\section{TÉCNICAS DE REPRODUÇÃO HUMANA ASSISTIDA}

As técnicas de reprodução humana assistida proporcionam a realização do sonho de muitos casais inférteis, já que por meio dela conseguem concretizar o projeto parental idealizado. Sendo assim, a procriação deve ser vista como um direito fundamental a todas a pessoas, principalmente diante da observância dos princípios da liberdade e do livre planejamento familiar, como a própria Constituição Federal garante em seu art. 226, § $7^{\circ}$ :

Art. 226. A família, base da sociedade, tem especial proteção do Estado:

$\S 7^{\circ}$ Fundado nos princípios da dignidade da pessoa humana e da paternidade responsável, o planejamento familiar é livre decisão do casal, competindo ao Estado propiciar recursos educacionais e científicos para o exercício desse direito, vedada qualquer forma coercitiva por parte de instituições oficiais ou privadas. ${ }^{11}$

Nesse sentido, a doutrinadora Maria Berenice Dias dispõe:

O uso das técnicas de reprodução assistida é um direito fundamental, consequência

8 Art. 226. A família, base da sociedade, tem especial proteção do Estado.

$[\ldots]$

$\$ 7^{\circ}$ Fundado nos princípios da dignidade da pessoa humana e da paternidade responsável, o planejamento familiar é livre decisão do casal, competindo ao Estado propiciar recursos educacionais e científicos para o exercício desse direito, vedada qualquer forma coercitiva por parte de instituições oficiais ou privadas. (BRASIL. Constituição (1988). Constituição da República Federativa do Brasil. Brasília, DF: Senado, 1988. Disponível em: http://www. planalto.gov.br/ccivil_03/Constituicao/Constituicao.htm. Acesso em: 10 abr. de 2019).

9 Art. 1565. Pelo casamento, homem e mulher assumem mutuamente a condição de consortes, companheiros e responsáveis pelos encargos da família [...]. §2 $2^{\circ}$ : O planejamento familiar é de livre decisão do casal, competindo ao Estado propiciar recursos educacionais e financeiros para o exercício desse direito, vedado qualquer tipo de coerção por parte de instituições privadas ou públicas (BRASIL. Código Civil (2002). Código Civil: Lei no 10.406, de 10 de janeiro de 2002. Brasília, DF: Câmara dos Deputados, 2002. Disponível em: http://www.planalto.gov.br/ccivil_03/ leis/2002/L10406.htm. Acesso em: 10.abr.2019).

10 BRASIL. Lei n⿳ 9.263, de 12 de janeiro de 1996. Regula o $\S 7^{\circ}$ do art. 226 da Constituição Federal, que trata do planejamento familiar, estabelece penalidades e dá outras providências. Disponível em: http://www.planalto.gov.br/ ccivil_03/leis/L9263.htm. Acesso em: 10.abr. 2019.

11 BRĀSIL. Constituição (1988). Constituição da República Federativa do Brasil. Brasília, DF: Senado, 1988. Disponível em: http://www.planalto.gov.br/ccivil_03/Constituicao/Constituicao.htm. Acesso em: 10 abr. de 2019. 
do direito ao planejamento familiar que decorre do princípio da liberdade. Impensável cercear este direito pelo advento da morte de quem manifestou a vontade de ter filhos ao se submeter às técnicas de reprodução assistida (...) A norma constitucional que consagra a igualdade da filiação não traz qualquer exceção. Assim, presume-se a paternidade do filho biológico depois do falecimento de um dos genitores. Ao nascer, ocupa a primeira classe dos herdeiros necessários. [...]. Vedar reconhecimento e direito sucessório a quem foi concebido mediante fecundação artificial post mortem pune, em última análise, o afeto, a intenção de ter um filho com a pessoa amada. Pune-se o desejo de realizar um sonho. ${ }^{12}$

As técnicas de reprodução humana assistida podem ser divididas entre inseminação artificial homóloga, inseminação artificial heteróloga e a cessão temporária de útero. Assim, fundamental é investigar a diferença entre tais técnicas e seus efeitos.

\subsection{Da inseminação artificial homóloga}

A inseminação artificial homóloga é a técnica de que utiliza o material genético do casal, futuros pais da criança. Método em que se "manipula gametas da mulher (óvulo) e do marido (sêmen)" e, cuja "fecundação, substitui a concepção natural, havida por meio da cópula. O meio artificial resulta da impossibilidade ou deficiência para gerar de um ou de ambos os cônjuges". ${ }^{13}$

No que tange a esta técnica, conforme disposto no artigo 1597, inciso IV, do Código Civil, presumem-se concebidos na constância do casamento os filhos havidos a qualquer tempo, quando se tratar de embriões excedentários, decorrentes de concepção artificial homóloga.$^{14}$

\subsection{Da inseminação artificial heteróloga}

Já a inseminação artificial heteróloga é aquela realizada com a junção do material genético da futura mãe da criança com o material genético de um terceiro doador anônimo. Para Maria Berenice Dias, “a fecundação artificial heteróloga ocorre por meio de doação de sêmen de um homem que não seja o marido, contando com a sua concordância". ${ }^{15}$

De acordo com o artigo 1597, inciso V, do Código Civil, presumem-se concebidos na constância do casamento os filhos havidos por inseminação artificial heteróloga, desde que tenha prévia autorização do marido. ${ }^{16}$

\subsubsection{DA CESSÃO TEMPORÁRIA DE ÚTERO}

12 DIAS, Maria Berenice. Manual das Sucessões. 2. ed. São Paulo: Revista dos Tribunais, 2011, p.123-124.

13 LÔBO, Paulo. Direito Civil: Famílias. São Paulo: Editora Saraiva, 2009, p. 200.

14 BRASIL. Código Civil (2002). Código Civil: Lei no 10.406, de 10 de janeiro de 2002. Brasília, DF: Câmara dos Deputados, 2002. Disponível em: http://www.planalto.gov.br/ccivil_03/leis/2002/L10406.htm. Acesso em: 10 abr. 2019.

15 DIAS, Maria Berenice. Manual de Direito das Família. 10 ed. São Paulo: Revista dos Tribunais, 2015. p. 387.

16 BRASIL. Código Civil (2002). Código Civil: Lei no 10.406, de 10 de janeiro de 2002. Brasília, DF: Câmara dos Deputados, 2002. Disponível em: http://www.planalto.gov.br/ccivil_03/leis/2002/L10406.htm. Acesso em: 10 abril de 2019. 
Enquanto que a técnica de cessão temporária de útero consiste na inseminação artificial de uma mulher estranha ao projeto parental, que aceita gerar a criança, por meio da transferência de embriões fecundados para o seu útero. O método é vulgarmente conhecido como "barriga de aluguel".

No ordenamento jurídico brasileiro, a única disposição legal que trata do assunto é a Resolução $n^{\circ}$ 2.168/2017, do Conselho Federal de Medicina (CFM), que dispõe que a "barriga de aluguel" só é permitida em casos de problemas médicos que impeçam a gestação da genitora.

Ainda, a cessão temporária de útero deve ser totalmente gratuita, não podendo ser onerosa, e a cedente do útero deve ter parentesco consanguíneo até o quarto grau com um dos futuros pais.

Entretanto, é fato notório que atualmente muitos casais para a concretização de seu projeto parental contratam cedentes de útero estranhas ao contexto familiar, de forma onerosa. Além disso, a despeito do previsto da Resolução do CFM, há muitas clínicas que agenciam e realizam a técnica de cessão de útero com cedentes mediante pagamento em pecúnia.

\section{DO INSTITUTO DA FILIAÇÃO NO ORDENAMENTO JURÍDICO}

Durante muito tempo restou assentado no ordenamento jurídico brasileiro o tratamento diferenciado entre os filhos de acordo com sua origem. Assim, a prole era classificada e dividida entre os filhos legítimos e os filhos ilegítimos, sendo que estes últimos tinham certos direitos e garantias negados por serem fruto de relacionamentos extraconjugais. ${ }^{17}$

O Código Civil de 1916 determinava que apenas a família advinda da relação matrimonial merecia proteção e reconhecimento de todos os seus direitos pelo Estado. Logo, persistiu por muito tempo a distinção entre os descendentes gerados na constância do matrimônio e os filhos adulterinos, de modo que "a situação conjugal do pai e da mãe se refletia na identificação dos filhos: conferia-lhes ou subtraía-lhes não só o direito à identidade, mas também o direito à sobrevivência" 18

Com o surgimento das Leis $n^{\circ} 4.737 / 42$ e 4.883/49, autorizou-se o reconhecimento dos filhos concebidos fora do matrimônio, porém, apenas após a dissolução do casamento do progenitor.

No ano de 1988, grandes avanços ocorreram com a promulgação da atual Constituição Federal, que consagrou a convivência familiar como um direito fundamental e adotou o princípio da proteção integral em relação à criança e ao adolescente, que foram elevados ao status de sujeitos de direitos. Tais fatos promoveram uma verdadeira revolução na identificação dos vínculos familiares e no próprio Direito de Família e seus institutos. ${ }^{19}$

De acordo com Sérgio Gischkow Pereira, hodiernamente não são mais permitidas expressões discriminatórias no contexto da filiação:

17 DIAS, Maria Berenice. Manual de Direito das Família. 10 ed. São Paulo: Revista dos Tribunais, 2015. p. 387. 18 DIAS, Maria Berenice. Manual de Direito das Família. 10 ed. São Paulo: Revista dos Tribunais, 2015 , p. 387. 19 DIAS, Maria Berenice. Manual de Direito das Família. 10 ed. São Paulo: Revista dos Tribunais, 2015, p. 288. 
$\mathrm{O}$ art. $227, \S 6^{\circ}$, da Constituição Federal é magnífico pelo que representa de avanço no Direito de Família pátrio. Quebra uma das mais deploráveis hipocrisias naquele ramo do Direito, de efeitos perniciosíssimos, consistente em "punir" os filhos ilegítimos por eventos no tocante aos quais não têm eles qualquer responsabilidade. ${ }^{20}$

O instituto da filiação foi uns dos temas tratados com mais ênfase pelo texto constitucional, visto que o Estado passou a reconhecer todos os tipos de entidades familiares e a igualdade entre os filhos, não existindo mais distinção no âmago da filiação.

A respeito disso, Maria Berenice Dias assevera que as famílias, nos tempos atuais, identificam-se pela comunhão plena de vidas, de amor, de afeto, gerando igualdade, liberdade, solidariedade e da responsabilidade recíproca. Na ocasião em que a família passou a ser constituída não apenas pelos laços consanguíneos, mas também pelos de afeto, ressaltando a igualdade e respeito mútuo, não existe mais pressupostos para que o Estado atue sobre as famílias de forma indevida. ${ }^{21}$

Com o advento do Código Civil de 2002, o instituto da filiação foi tratado referido pelo diploma à luz dos princípios constitucionais, de forma que o Código consagrou o direito de filiação sem qualquer tipo de discriminação entre os filhos. Consoante o art. 1.596 do diploma, os filhos, havidos ou não da relação de casamento, ou por adoção, terão os mesmos direitos e qualificações, proibidas quaisquer designações discriminatórias relativas à filiação. ${ }^{22}$

\section{CIRCUNSTÂNCIAS PÔLEMICAS DA REPRODUÇÃO HUMANA ASSISTIDA}

\subsection{Da filiação e da inseminação artificial post mortem}

O artigo 1596, inciso III, do Código Civil proclama que presumem-se concebidos na constância do casamento os filhos havidos por fecundação artificial homóloga, mesmo que falecido o marido. Portanto, os filhos nascidos por qualquer técnica de inseminação artificial possuem o direito de filiação, independentemente se gerados antes ou depois de uns dos genitores.

A inseminação artificial post mortem foi possibilitada diante dos avanços das técnicas de reprodução assistida, que permitem o congelamento de material genético e de embriões fecundados. Este método é realizado mediante a utilização do material genético de um indivíduo já falecido para a concretização do projeto parental.

Quanto à forma do consentimento, a Resolução do CFM n ${ }^{\circ} 21.68 / 2017$, assim dispõe:

20 PEREIRA, Sérgio Gischkow. Algumas questões de direito de família na nova constituição. A igualdade na filiação, inclusive para adotados. Revista AJURIS, v. 16, n. 45, mar. 1989. p. 150.

21 DIAS, Maria Berenice. Manual de Direito das Famílias. 5. ed. São Paulo: Revista dos Tribunais, 2009. p.144.

22 BRASIL. Código Civil (2002). Código Civil: Lei no 10.406, de 10 de janeiro de 2002. Brasília, DF: Câmara dos Deputados, 2002. Disponível em: http://www.planalto.gov.br/ccivil_03/leis/2002/L10406.ht. Acesso em: 10.abr.2019. 
É permitida a reprodução assistida post-mortem desde que haja autorização prévia específica do (a) falecido (a) para o uso do material biológico criopreservado, de acordo com a legislação vigente. ${ }^{23}$

A problemática da inseminação artificial post mortem é que o filho ainda não está vivo, nem concebido por ocasião da abertura da sucessão. Conforme o artigo 1798 do Código Civil, os filhos devem estar vivos, ou pelo menos concebidos, para participar da vocação hereditária. ${ }^{24}$

Porém, existe a possibilidade da sucessão testamentária, conforme estipula o art. 1.799, inciso I, do Código Civil, ${ }^{25}$ no qual é legítimo o desejo de última vontade do testador em contemplar como herdeiro pessoas ainda não nascidas.

Nesse sentido, Guilherme Calmon Nogueira da Gama leciona:

[...] a capacidade testamentária passiva se reveste de alguns contornos bastante particulares, permitindo, por exemplo - sob a modalidade de instituição testamentária condicional -, a disposição em favor de ente que sequer tem existência física e, simultaneamente, jurídica, como na hipótese envolvendo o filho eventual de pessoa determinada existente por ocasião do falecimento do testador. ${ }^{26}$

Contudo, é necessário respeitar o lapso temporal de 02 (dois) anos para o nascimento ou concepção da prole eventual, visto que se decorrido esse prazo, a cota reservada irá ser dividida entre os herdeiros necessários, nos termos do $\S 4^{\circ}$ do art. 1800 do Código Civil.

Logo, a problemática, está em relação ao filho póstumo, na hipótese do de cujus não deixar testamento assegurando o direito da prole eventual.

Dessa forma, se faz necessário a criação de lei específica para regulamentação e para que se assegure, com maior segurança jurídica, os direitos de sucessão do concebido post mortem, uma vez que está assegurado o direito de filiação deste.

\subsection{Bebê medicamento}

A técnica do bebê medicamento é conhecida por ser o método em que, por meio de um diagnóstico genético pré-implantacional, são escolhidos embriões livres de anomalias genéticas e

23 BRASIL. Resolução 2.168/2017 do Conselho Federal de Medicina. Disponível em: http://www.portalmedico. org.br/resolucoes/CFM/2015/2121_2015.pd. Acesso em: 10 de abr. 2019.

24 BRASIL. Código Civil (2002). Código Civil: Lei no 10.406, de 10 de janeiro de 2002. Brasília, DF: Câmara dos Deputados, 2002. Disponível em: http://www.planalto.gov.br/ccivil_03/leis/2002/L10406.htm. Acesso em: 10. abr. 2019.

25 Art. 1.799. Na sucessão testamentária podem ainda ser chamados a suceder:

I - os filhos, ainda não concebidos, de pessoas indicadas pelo testador, desde que vivas estas ao abrir-se a sucessão; II - as pessoas jurídicas;

III - as pessoas jurídicas, cuja organização for determinada pelo testador sob a forma de fundação. (BRASIL. Código

Civil (2002). Código Civil: Lei no 10.406, de 10 de janeiro de 2002. Brasília, DF: Câmara dos Deputados, 2002. Disponível em: http://www.planalto.gov.br/ccivil 03/leis/2002/L10406.htm. Acesso em: 10. abr. 2019).

26 GAMA, Guilherme Calmon Nogueira da. Capacidade para testar, para testemunhar e para adquirir por testamento. In: HIRONAKA, Giselda Maria Fernandes Novaes; PEREIRA, Rodrigo da (coords.). Direito das Sucessões. 2. ed. Belo Horizonte Del Rey, 2007, p. 213. 
compatíveis com um irmão "doente", que precisa de um transplante ou doação de sangue ou órgão.

O Conselho Federal de Medicina, por meio da Resolução n. 2.168/2017 ${ }^{27}$ autoriza seleção de embriões compatíveis com algum filho do caso, já diagnosticado com uma doença.

A principal crítica em relação ao bebê medicamento é o uso desse filho para a cura do irmão mais velho, visto que muitos percebem na técnica a instrumentalização do novo filho.

Porém como entende Jean Longeneaux, é muito questionável a possibilidade de que uma criança tenha sido concebida unicamente em razão de si mesma e não em razão dos desejos e anseios de seus genitores em constituir família. ${ }^{28}$

A discussão sobre o bebê medicamento está relacionada também ao temor da utilização de técnicas de eugenia e o transplante de órgãos e tecidos. Para evitar tais práticas, é necessária a fiscalização por parte do Estado, visto que estas podem ser utilizadas de maneira indiscriminada e não limitada a fins terapêuticos.

\subsection{Direito ào anonimato do doador na reprodução assistida}

O terceiro doador do material genético na reprodução humana assistida possui o direito de ter seu anonimato preservado. Como assevera Alessandro Brandão Marques, este sigilo, tão importante e frisado a todo momento, tem como causa a intenção de integração e preservação da criança gerada com sua futura família. Além disso, visa prevenir eventuais interferências do doador de material genético nos laços familiares. ${ }^{29}$

A Resolução do Conselho Federal de Medicina $n^{\circ} 2.168 / 2017{ }^{30}$ determina que os doadores não devem conhecer a identidade dos beneficiários dos materiais genéticos, tão pouco esse conhecerem a identidade do doador, visto que o sigilo entre as partes deve ser preservado. No entanto, a mesma resolução, permite que, em situações excepcionais, por motivos clínicos, informações sobre o terceiro doador sejam repassadas aos médicos e aos idealizadores do projeto parental.

O ilustríssimo Eduardo de Oliveira Leite justifica o anonimato do doador da seguinte maneira:

[...] a doação de gametas não gera ao seu autor nenhuma conseqüência parental relativamente à criança daí advinda. A doação é abandono a outrem, sem arrependimento sem possibilidade de retorno. É medida de generosidade, medida filantrópica. Essa consideração é o fundamento da exclusão de qualquer vínculo de filiação entre doador e a criança oriunda da procriação. É, igualmente, a

$\overline{27}$ BRASIL. Resolução 2.121/2015 do Conselho Federal de Medicina. Disponível em: http://www. portalmedico.org.br/resolucoes/CFM/2015/2121 2017.pdf. Acesso em: 10 abr. 2019.

28 LONGNEAUX, Jean Michel. Apud. FÉ $\bar{O}$, Christina. VIEIRA, Tereza Rodrigues. Eugenia e o Direito de nascer ou não com deficiência: algumas questões em debate. In VIEIRA, Tereza Rodrigues (org). Ensaios de bioética e direito. Brasília: Consulex, 2012, p.58.

29 MARQUES, Alessandro Brandão. Questões polêmicas decorrentes da doação de gametas na inseminação artificial heteróloga. Jus Navigandi, Teresina, a. 7, n. 92, 3 out. 2003. Disponível em: http://jus.com.br/revista/ texto/4267. Acesso em: 10 de abr. 2019.

30 BRASIL. Resolução 2.121/2015 do Conselho Federal de Medicina. Disponível em: http://www. portalmedico.org.br/resolucoes/CFM/2015/2121_2017.pdf. Acesso em: 10. abr. 2019. 
justificação do princípio do anonimato. ${ }^{31}$

Porém, diante do direito ao anonimato do doador, surge o direito ao conhecimento da origem genética da pessoa gerada, o que gera uma controvérsia jurídica.

Como pontua Belmiro Pedro Welter:

[...] em qualquer caso, o filho, o pai e a mãe têm o direito de investigar e/ou de negar a paternidade ou a maternidade biológica, como parte integrante de seus direitos de cidadania e de dignidade de pessoa humana. No entanto, o direito ao anonimato do doador também é protegido pelo princípio, uma vez que o direito à intimidade é um desdobramento dos direitos fundamentais que existe justamente para garantir a dignidade da pessoa humana. ${ }^{32}$

Nessa esteira, o direito de reconhecimento da origem biológica é o direito do concebido conhecer sua ascendência genética.

A respeito do assunto, Tycho Brache Fernandes diz que estará gerando um desrespeito e discriminação à criança nascida por meio de umas das técnicas de reprodução assistida, ao negar o ajuizamento de ação investigatória, uma vez que a criança nascida por meio de relações sexuais possuem tal direito, devendo ser assegurado para os que não foram concebidos de forma natural as mesmas garantias. ${ }^{33}$

A dimensão do princípio da dignidade da pessoa humana na solução de conflitos relacionados à família se apresenta de forma que é ele o norteador dos direitos fundamentais presentes na Constituição Federal de 1988.

Dessa forma, Edílson Pereira de Farias dispõe que o princípio da dignidade da pessoa humana cumpre um papel fundamental na configuração do estado constitucional, sendo fonte jurídica para os direitos fundamentais. É um princípio que possui valor e gera coerência ao conjunto dos direitos fundamentais. Assim sendo, o princípio da dignidade da pessoa humana, consagrado na Constituição Federal de 1988, traduz o rol de direitos e garantias fundamentais que o título II da supra Carta citada trás. ${ }^{34}$

Partindo desse pensamento, é evidente que o anonimato do doador é assunto que repercute incansáveis discussões, pois a lei não define até que ponto o mesmo é protegido.

Portanto, é evidente que a ausência de uma legislação específica que regulamente as técnicas de reprodução humana assistida proporciona um cenário de grandes controvérsias e problemas jurídicos, tais como os embates existentes diante do direito ao anonimato e o direito ao conhecimento da origem genética, ambos correspondentes aos direitos de personalidade.

\footnotetext{
31 LEITE, Eduardo de Oliveira. Procriações artificiais e o direito: aspectos médicos, religiosos, psicológicos, éticos e jurídicos. São Paulo: Revista dos Tribunais, 1995.

32 WELTER, Belmiro Pedro. Igualdade entre as filiações biológica e socioafetiva. São Paulo: Editora Revista dos Tribunais, 2003.

33 FERNANDES, Tycho Brahe. A Reprodução Assistida em face da Bioética e do Biodireito. Ed. Diploma Legal, Florianópolis, SC, 2000, p. 86.

34 FARIAS, Edílson Pereira de. Colisão de direitos: a honra, a intimidade, a vida privada e a imagem versus a liberdade de expressão e informação. Porto Alegre: Sergio Antônio Fabris, 1996, p. 54.
} 


\section{CONSIDERAÇÕES FINAIS}

A presente pesquisa destacou, em suas reflexões, que o princípio da dignidade da pessoa humana é de extrema importância para o ordenamento jurídico, inclusive para as famílias que se submetem a métodos de reprodução humana assistida. $\mathrm{O}$ uso das técnicas de reprodução humana assistida, tanto na modalidade homóloga como na heteróloga, acarreta diversas controvérsias frente ao Direito de Família e Sucessões.

No tocante à inseminação artificial post mortem, a norma legal reconhece o direito à filiação. Já quanto ao bebê medicamento, as indagações giram em torno da possibilidade de cometimento de práticas antiéticas ligadas à eugenia e ao transplante de órgãos e tecidos, devendo o Estado adotar uma fiscalizar que impeça tais práticas, uma vez que o bebê medicamento é um importante avanço para medicina e na própria família.

Já em relação, ao direito do anonimato do doador nas reproduções humanas assistidas heterólogas, a grande questão que surge é quanto ao direito de anonimato do doador frente ao direito de reconhecimento da origem genética, dois direitos fundamentais que se contrapõem.

Portanto, é evidente a necessidade de criação de normas legais que possam dirimir as controvérsias existente no campo das técnicas de inseminação artificial, para impedir o cerceamento dos direitos dos envolvidos.

\section{REFERÊNCIAS BIBLIGRÁFICAS}

ALBUQUERQUE FILHO, Carlos Cavalcanti de. Fecundação artificial post mortem e o Direito Sucessório. In: PEREIRA, Rodrigo da Cunha (Coord.). Família e dignidade humana. São Paulo: IOB Thomson, 2006.

BRASIL. Código Civil (2002). Código Civil: Lei no 10.406, de 10 de janeiro de 2002. Brasília, DF: Câmara dos Deputados, 2002. Disponível em: http://www.planalto.gov.br/ ccivil_03/leis/2002/L10406.htm. Acesso em: 10 de abr. 2019.

BRASIL. Constituição (1988). Constituição da República Federativa do Brasil. Brasília, DF: Senado, 1988. Disponível em: < http://www.planalto.gov.br/ccivil_03/Constituicao/Constituicao. htm>. Acesso em: 10 abr. de 2019.

BRASIL. Lei n. 883, de 21 de outubro de 1949. Disponível em: http://www.planalto.gov.br/ ccivil_03/LEIS/1930-1949/L0883.htm. Acesso em: 10 de abr. 2019.

BRASIL. Resolução 2.168/2017 do Conselho Federal de Medicina. Disponível em: http:// www.portalmedico.org.br/resolucoes/CFM/2015/2121_2015.pd. Acesso em: 10 de abr. 2019.

DIAS, Maria Berenice. Manual das Sucessões. 2. ed. São Paulo: Revista dos Tribunais, 2011, p.123-124. 
DIAS, Maria Berenice. Manual de Direito das Famílias. 5. ed. São Paulo Revista dos Tribunais, 2009.

DIAS, Maria Berenice. Manual de Direito das Família. 10 ed. São Paulo: Revista dos Tribunais, 2015.

FARIAS, Edílson Pereira de. Colisão de direitos: a honra, a intimidade, a vida privada e a imagem versus a liberdade de expressão e informação. Porto Alegre: Sergio Antônio Fabris, 1996.

FERNANDES, Tycho Brache. A reprodução assistida em face da bioética: aspectos do direito de família e do direito das sucessões. Florianópolis: Diploma Legal, 2000.

FERNANDES, Tycho Brahe. A Reprodução Assistida em face da Bioética e do Biodireito. Ed. Diploma Legal, Florianópolis, SC, 2000, p. 86.

GAMA, Guilherme Calmon Nogueira da. Capacidade para testar, para testemunhar e para adquirir por testamento. In: HIRONAKA, Giselda Maria Fernandes Novaes; PEREIRA, Rodrigo da (coords.). Direito das Sucessões. 2. ed. Belo Horizonte Del Rey, 2007.

KANT, Immanuel. Fundamentação da metafísica dos costumes e outros escritos. São Paulo: Martin Claret, 2004.

LEITE, Eduardo de Oliveira. Procriações artificiais e o direito: aspectos médicos, religiosos, psicológicos, éticos e jurídicos. São Paulo: Revista dos Tribunais, 1995.

LÔBO, Paulo. Direito Civil: Famílias. São Paulo: Saraiva, 2009.

LONGNEAUX, Jean Michel. Apud. FÉO, Christina. VIEIRA, Tereza Rodrigues. Eugenia e o Direito de nascer ou não com deficiência: algumas questões em debate. In: VIEIRA, Tereza Rodrigues (org.). Ensaios de bioética e direito. Brasília: Consulex, 2012.

MARQUES, Alessandro Brandão. Questões polêmicas decorrentes da doação de gametas na inseminação artificial heteróloga. Jus Navigandi, Teresina, a. 7, n. 92, 3 out. 2003. Disponível em: http://jus.com.br/revista/texto/4267. Acesso em: 10 de abr. 2019.

MIRANDA, Jorge. Manual de direito constitucional. tomo IV. 2. ed. Coimbra Editora, 1993.

PEREIRA, Sérgio Gischkow. Algumas questões de direito de família na nova constituição. A igualdade na filiação, inclusive para adotados. Revista AJURIS, v. 16, n. 45, mar. 1989.

RABENHORST, Eduardo Ramalho. Dignidade humana e moralidade democrática. Brasília: Brasília Jurídica, 2001.

SARLET, Ingo Wolgang. Dignidade da pessoa humana e direitos fundamentais na Constituição de 1988. Porto Alegre: Livraria do Advogado, 2001.

WELTER, Belmiro Pedro. Igualdade entre as filiações biológica e socioafetiva. São Paulo: 
Editora Revista dos Tribunais, 2003.

Recebido em: 23/10/2019.

Aprovado em: 15/11/2019. 